\title{
Development of high-input systems of cereal production in Europe
}

\author{
A. Falisse and B. Bodson \\ Faculté des Sciences Agronomiques de l'Etat, B-5800 Gembloux, Belgium
}

\section{Introduction}

The recent history of cereal crops in Western Europe is associated with the names of several researchers who, on the basis of increased knowledge of the soil/climate medium and a greater understanding of plant physiology, have proposed new techniques in crop production, thus opening the way for rapid intensification which, from 1950 to 1980 , have resulted in a doubling of yields.

Coic (1960) presented the results of an experiment on nitrogen fertilization of cereals, especially on the role of nitrogen on plant growth and development, grain yield and quality. He indicated also his reasoning behind the 'splitting' of nitrogen fertilizer during the course of the growing season. He proposed, for example:

(a) No nitrogen top dressing before the end of winter in winter cereals;

(b) Essential top dressings to be given to wheat during the course of tillering (first application) and, especially, at stem extension (second application);

(c) In certain conditions, the advantage of a late supply of nitrogen i.e. up to the end of flowering, by application of a complementary dose of nitrogen fertilizer at ear emergence.

In 1967, Laloux proposed a method of crop management carried out in the edaphic, climatic and agricultural conditions of the Belgian loam region. This method is characterized, essentially, by the desire to avoid, in so far as it is possible, excessive vegetation density in cereal crops. These low densities reduce the risks of lodging and the development of disease epidemics, thus allowing the formation of relatively low ear numbers, all individually with high productive capacity (high fertility, high grain weight). To achieve these objectives the following rules were recommended:

(a) Sowing densities which will give rise to about 200 plants per $\mathrm{m}^{2}$ at the beginning of tillering; this applies to crops sown at a normal date i.e. end of October to beginning of November;

(b) Supplying nitrogen fertilizer according to a scheme similar to that given by Coic (1960), i.e. using moderate doses up to the end of tillering, increasing the nitrogen application at stem extension (leaf sheath erect stage), extending nitrogen nutrition until the end of vegetation by means of a moderate 

application around the 'flag leaf stage' with the intention of complementing
nitrogen supplies from the soil, as a result of mineralization.

The method presented rigorous guidelines (precise objectives for plant and ear and, at the same time, a flexibility in relation to nes and the stages of application) nitrogen for different soil humus in relation to the definition of the quantity of climatic conditions, which demand contents, previous cropping and autumn/winter these husbandry practices, new ted different annual adaptations. In addition to weed control, fungicide protection, rated. This method has been successful in Belgium and neighbouring regions, not only
because of its capacity to constantly founders have ensured widespread achieve high yields but also because its means of conferences, debates, literature and in of farmers with the method by with the farmers themselves. However, literature and in following through its application been associated with certain problems, outside Belgium the method has sometimes aspects of the metho to unsuitability of certain (varieties, crop sequences, etc.). This has soil, climate and agricultural practices usefulness of the late application of nitrogen, the case with low seed densities, the and the nature of the plant protection regimes.

Since its initiation in protection regimes.

organizations, as well as private, interest in the method has led official research systems in many western several other meanings in this context:

(a) Some involve a 'complete method' covering the whole crop period from sowing to harvest, i.e. a collection of directives concerning crop period from sowing weed control, fungicide protection and other terning sowing, nitrogen fertilizer, eventually (Laloux method, Schleswig-Holstein method which will be useful input methods of ADAS, Heyland system in Bigh-

(b) Others involve a 'limited method' dealing in Bonn region, and so on). quantity of nitrogen fertilizer (N-min methody with the determination of the recently included in a general method, ITCF method of balances rendez-vous de blé').

However, the two systems which are followed most enthusiastically and which have aroused the greatest controversy are the Laloux and the Schleswig-Holstein
systems and these are briefly described.

\section{The 'Laloux System' - a semi-intensive system}

Precise and complete references to this system can be found in French language publications (Laloux, 1967; Laloux, Falisse and Poelaert, 1975; Laloux et al., 1980; (Laloux, Falisse and several resumés of the method in the English language






\section{Type of rotations}

Rotation may be varied, but very rarely is there a repetition of the same cereal (two or more successive wheats, or barleys); winter cereals are generally grown. The more frequent rotation is sugar beet (yielding $50-70 \mathrm{tha}^{-1}$ of roots with a $16 \%$ sugar content), winter wheat and six-row winter barley.

\section{Sowing dates}

The sowing of winter wheat is, on average, relatively late, due to the presence in the rotation of sugar beet which is harvested from October to December. The drilling period extends, thus, from 15 October to 15 January and sometimes up to the end of February.

\section{Sowing densities}

The seed rate is low compared with other systems, ranging from 225 grains $\mathrm{m}^{-2}$ for end of October sowings to 375 grains $\mathrm{m}^{-2}$ for December or later sowings. Generally it will be adapted to obtain populations of about 200 plants $\mathrm{m}^{-2}$ at the end of winter.

\section{Ear densities}

The amount generally achieved is between 400 and $550 \mathrm{ears}^{-2}$, prior to harvest.

\section{Nitrogen fertilizer}

The total nitrogen quantity must be adapted to:

(a) The climatic conditions of the year, which influence mineralization and leaching;

(b) The amount of nitrogen produced by mineralization, depending on the humus content of the soils;

(c) The amount of fertilizer remaining in the soil from the previous crop; and

(d) The type of previous crop.

On average, the total nitrogen fertilizer dose is $140 \mathrm{~kg} \mathrm{ha}^{-1}$ for 'normal' climatic conditions in a situation where the preceding crop was sugar beet with tops removed from the field, grown on an acid soil, with a low humus content $(2 \%)$. The 'splitting' is normally programmed in three applications: at full tillering stage (growth stage 3-4), possibly mid-March, $30 \mathrm{~kg} \mathrm{Nha}^{-1}$; at leaf sheath erect stage (growth stage 5), possibly mid-April, $80 \mathrm{~kg} \mathrm{~N} \mathrm{ha}^{-1}$; at the flag leaf stage (growth stage 8$), 30 \mathrm{~kg} \mathrm{Nha}^{-1}$.

\section{Growth regulators}

At the beginning of stem extension (growth stage 5) on a growing crop a rate of $1-1.5 \ell \mathrm{ha}^{-1}$ of CCC (at $46 \%$ a.i.) is applied.

\section{Weed control}

This is carried out as early as possible, in particular by pre-emergence treatment or by treatment at the beginning of spring. 


\section{Crop protection}

Generally, a single broad-spectrum treatment is carried out around earing (growth stage 10.4) in order to give protection against all the diseases of the upper vegetative layers. The more damaging diseases in the climatic conditions of the region include mildew, rusts, Septoria and Fusaria of the leaves and ears. The low doses, earried out with the aid of a mixture of active ingredients at relatively low doses, e.g. $150 \mathrm{~g} \mathrm{ha}^{-1}$ benomyl plus $3 \mathrm{~kg}$ sulphur plus $2 \mathrm{~kg}$ maneb or $125 \mathrm{~g} \mathrm{ha}^{-1}$ triadimefon plus $1.25 \mathrm{~kg}$ captafol. In some particular cases only a control of lower there is an early attack is achieved by an application of MBC at stem elongation. If second ne rust or mildew an early treatment is given at the second node/flag leaf stage. If conditions are very favourable to the development of out. Insect a second application (in addition to that at ear emergence) is carried present above a defined damaging the and is limited to the control of aphids, if

\section{The 'Schleswig-Holstein System' - a very intensive system}

This system is very intensive in the sense that it recommends the use of all the means of production at a very high level (high inputs) and ensures, in the specific region, very high yields (high outputs). A number of publications exist on the
subject, e.g. Effland (1981).

\section{Type of rotations}

Generally, oilseed rape, winter wheat, winter barley (six-row) but also sugar beet, winter wheat, winter barley.

\section{Sowing dates}

On average very early, after oilseed rape; sometimes after winter oats, from 20 September to 10 October; after sugar beet, sown until mid-November.

\section{Sowing densities}

$190-230$ and up to $280 \mathrm{~kg} \mathrm{ha}^{-1}$ or $400-550$ grains $\mathrm{m}^{-2}$, according to the date of
sowing.

\section{Row spacing}

The row spacing is as narrow as possible, $11-14 \mathrm{~cm}$.

\section{Plant densities}

At the end of winter, $400-500$ plants $\mathrm{m}^{-2}$ are obtained, and up to 550 for late
sowings. 


\section{Ear densities}

At least $550-600$ ears $\mathrm{m}^{-2}$ are achieved and, on better soils, more than 700 ears $\mathrm{m}^{-2}$.

\section{Nitrogen fertilizer}

The overall level of nitrogen is very high in the order of $170-235 \mathrm{~kg} \mathrm{Nha}^{-1}$. 'Splitting' is programmed in at least three applications: end of January to beginning of February, $90-130 \mathrm{~kg} \mathrm{~N} \mathrm{ha}^{-1}$; beginning of stem extension (growth stage 3-4), $20-25 \mathrm{~kg} \mathrm{Nha}^{-1}$; before earing (growth stage $8-10$ ), $60-80 \mathrm{~kg} \mathrm{~N} \mathrm{ha}^{-1}$ (the latter application is often subdivided into two or three 'splits'). There is little influence of annual climatic conditions, preceding crops, etc. on the total nitrogen dose. Oligo-elements comprising a mixture of six minor elements (Fretilon-Combi) are automatically applied with the late application of nitrogen.

\section{Growth regulators}

CCC is used systematically; the doses vary according to the variety, from $2-3.5 \mathrm{eha}^{-1}$, applied in two or three splits (growth stage 3-4, again at growth stage 5-7 and growth stage 8 ).

\section{Fungicide protection}

A number of treatments (at least three) are used, directed against foliar and ear diseases (two treatments at least, with broad spectrum activity resulting from a mixture of two or three active ingredients, plus an insecticide in many cases). The fungicide protection programme is very thorough and aims to protect the crop against all risks.

To summarize, the method involves the establishment, growth and development of a high number of plants. The number of ears will be high and the main stems play a major role vs. that of the tillers. All inputs - nitrogen, growth regulators, fungicides, seeds - are used at high levels and generally prove themselves to be profitable, especially in early-drilled crops.

\section{A comparison between the systems}

It is interesting to compare the new systems with the old-established or conventional ones; innumerable comparisons have been made and some of the more interesting results are discussed below. In France, Pellot (1981) and FaivreDupaigre (1981) reported the results of a network of trials carried out over five years in the North Paris Basin area; the objective of the trials was the comparison of three systems. System 1, referred to as "intensive" was characterized by the establishment of wheat of very high yield potential (high-yielding varieties, drilled very early), and by the suppression of all limiting factors of production, i.e. by using those techniques which permit the maximum yield to be attained. System 2, referred to as 'moderate', envisaged the attainment of high yields by using non-systemic techniques, except when it appeared profitable to do so at the moment of their application. System 3, referred to as 'extensive', was concerned 
with establishing wheat of average potential (hardy variety, drilled much later) with a limit as regard costs of production.

TABLE 32.1. Comparison of three systems of cereal production in the North Paris Basin area of France from 1976 to 1981 . From Ambolet and Maumene (1981)

\begin{tabular}{llll}
\hline System & $\begin{array}{l}\text { Yield } \\
\left(\text { t ha }^{-1}\right)\end{array}$ & $\begin{array}{l}\text { Variable costs } \\
\left(F^{-1} \mathrm{ha}^{-1}\right)\end{array}$ & $\begin{array}{l}\text { Gross margin } \\
\left(\text { FF ha }^{-1}\right)\end{array}$ \\
\hline 1 (intensive) & 7.42 & 1846 & 5570 \\
2 (moderate) & 6.21 & 1116 & 5092 \\
3 (extensive) & 5.37 & 864 & 4502 \\
\hline
\end{tabular}

The results are shown in Table 32.1 and can be summarized as follows:

(a) System 1, the 'intensive' system, gives an average of $1.2 \mathrm{tha}^{-1}$ more than System 2 , the 'moderate' system; System 3 gives an average of $0.8 \mathrm{tha}^{-1}$ less than
System 2;

(b) Economic results: the gross margin (produce value less variable costs) was much higher for System 1 (411 FF ha ${ }^{-1}$ more than System 2 and $1039 \mathrm{FF} \mathrm{ha}^{-1}$ more than System 3).

The conclusions of the authors were that, in this region, intensification is often profitable. It should always be noted that the results are strongly dependent on establishment conditions of the wheat crop (in particular the drilling dates) which

In the UK, the level of potential yield, which is an integral part of the system. England and Wales. The four systems complts of trials carried out by ADAS in Holstein system, Loure systems compared were as follows: Schleswignitrogen levels. Table 32 sym, a low cost system and the ADAS system of high with those of earlier years.

TABLE 32.2. Comparison of systems of cereal production in England and Wales in 1980. From Hughes
(1981)

\begin{tabular}{llll}
\hline System & $\begin{array}{l}\text { Yield } \\
\left(\text { t ha }^{-1}\right)\end{array}$ & $\begin{array}{l}\text { Variable costs } \\
\left(F F a^{-1}\right)\end{array}$ & $\begin{array}{l}\text { Gross margin } \\
\left(F F \text { h }^{-1}\right)\end{array}$ \\
\hline Schleswig-Holstein & 8.54 & 2380 & 6140 \\
Laloux & 8.68 & 1872 & 6811 \\
Low cost & 7.68 & 1260 & 6402 \\
ADAS high nitrogen & 8.70 & 1803 & 6871 \\
\hline
\end{tabular}

In Belgium, Laloux et al. $(1980 ; 1982)$ presented the results of trials carried out at Gembloux and in other regions; the actual conclusions were as follows (Tables 32.3
and 32.4): 
TABLE 32.3. Effects of sowing densities on yield. From Laloux et al (1982)

\begin{tabular}{lll}
\hline $\begin{array}{l}\text { Date of sowing } \\
\text { (Gembloux) }\end{array}$ & \multicolumn{2}{c}{ Densities } \\
\cline { 2 - 3 } & $220{\text { grains } m^{-2}}^{2}$ & $450{\text { grains } ~^{-2}}^{-2}$ \\
\hline 1978: 17 November & 7868 & 7658 \\
1979: 31 October & 5367 & 5483 \\
1980: 19 October & 5829 & 5976 \\
1981: 14 November & 6441 & 7084 \\
Average & 6376 & 6550 \\
\hline
\end{tabular}

TABLE 32.4. Comparison of sowing densities. From Laloux et al. (1982)

\begin{tabular}{|c|c|c|c|c|c|}
\hline \multirow[t]{2}{*}{ Location } & \multirow{2}{*}{$\begin{array}{l}\text { Dates of sowing } \\
1981\end{array}$} & \multicolumn{2}{|c|}{ Low densities } & \multicolumn{2}{|c|}{ High densities } \\
\hline & & Grains $m^{-2}$ & $\begin{array}{l}\text { Yield } \\
\left(\mathrm{kg} \mathrm{ha}^{-1}\right)\end{array}$ & Grains $m^{-2}$ & $\begin{array}{l}\text { Difference } \\
\left(\mathrm{kg} \mathrm{ha}^{-1}\right)\end{array}$ \\
\hline Fraire & 11 October & 275 & 7952 & 400 & -314 \\
\hline Thisnes & 29 October & 300 & 8191 & 450 & +25 \\
\hline Ath & 21 October & 300 & 4980 & 450 & 0 \\
\hline Thuin & 15 October & 360 & 5979 & 550 & +177 \\
\hline
\end{tabular}

(1) There was little advantage in increasing systematically the sowing densities; drillings carried out between 11 October and 15 November, with sowing densities of between 275 and 360 grains $\mathrm{m}^{-2}$ were, at least, equivalent to the much higher seed rates of 400-550 grains $\mathrm{m}^{-2}$.

(2) The 'splitting' of CCC (with much higher total doses) had, on average, little effect on yield;

(3) A comparison between the Laloux system and the Schleswig-Holstein system during the course of three years, gave the results shown in Table 32.5.

It may be concluded therefore that there was:

(i) a higher yield of nearly $0.4 \mathrm{t}$ for the Schleswig-Holstein system;

(ii) however, a supplementary cost per hectare, equivalent to $480 \mathrm{~kg}$ of grain for this same method;

(iii) therefore, a higher gross margin for the Laloux system on average, except in the course of the third year of trials with better results being recorded for the Schleswig-Holstein system.

TABLE 32.5. Comparison between Laloux system and Schleswig-Holstein system - Gembloux - 1979-81. From Laloux et al. (1982)

\begin{tabular}{lllc}
\hline Year & $\begin{array}{l}\text { Laloux system } \\
\left(\mathrm{kg} \mathrm{ha}^{-1}\right)\end{array}$ & $\begin{array}{l}\text { Schleswig-Holstein system } \\
\left(\mathrm{kg} \mathrm{ha}^{-1}\right)\end{array}$ & $\begin{array}{l}\text { Differences } \\
\left(\mathrm{kg} \mathrm{ha}^{-1}\right)\end{array}$ \\
\hline 1979 & 5366 & 5483 & 117 \\
1980 & 5568 & 5955 & 387 \\
1981 & 6441 & 7084 & 643 \\
Average & 5792 & 6174 & 382 \\
\hline
\end{tabular}




\section{Aspects of intensive systems}

\section{Crop planting and sowing}

Intensification with regard to sowing concerns the date of sowing, the quality of the spacings.
seed the densitribution, in particular, inter-row

\section{Date of sowing}

It is generally agreed that, all other factors being equal, on average early sowing results in higher yields. Table 32.6 illustrates this phenomenon between the two regions under consideration. A number of other examples could also be given. Nevertheless, limits do exist, e.g. in 1974 and 1975 it was noted in France that the the earliest sown winter barleys a much greater sensitivity to yellow rust attacks; by aphids and, therefor barleys had a much greater sensitivity to autumnal attacks

TABLE 32.6. Yield as a function of sowing dates

\begin{tabular}{|c|c|c|c|}
\hline \multicolumn{2}{|c|}{$\begin{array}{l}\text { Schleswig-Holstein } \\
\text { Futterkamp (1978) }\end{array}$} & \multicolumn{2}{|c|}{$\begin{array}{l}\text { Belgium } \\
\text { Gembloux (1981) }\end{array}$} \\
\hline Sowing date & $\begin{array}{l}\text { Yield } \\
\left(t \text { ha }^{-1}\right)\end{array}$ & Sowing date & $\begin{array}{l}\text { Yield } \\
\left(t \text { ha }^{-1}\right)\end{array}$ \\
\hline $\begin{array}{l}\text { End September } \\
10 \text { October } \\
\text { End November }\end{array}$ & $\begin{array}{r}10.64 \\
9.88 \\
8.34\end{array}$ & $\begin{array}{l}16 \text { September } \\
29 \text { October } \\
17 \text { December }\end{array}$ & $\begin{array}{l}7.80 \\
7.20 \\
5.00\end{array}$ \\
\hline
\end{tabular}

In other words, early sowing dates generally lead to an increase in yields but, equally, demand an intensification of husbandry practices (e.g. crop protection); yields is high and, in many cases, mastified when the level of reasonably attainable

\section{Sowing and ear densities}

The determination of sowing density engenders considerable debate and there is no varieties of low tillering optimum ear populations. It is generally acknowledged that drillings should be carried capacity should be sown at higher densities and that late systems differ in their target ear population seed rates than earlier drillings. The sowing rates. As previously stated the differences between system are between 450 and 550 , the optimum ear populations for the Laloux 220 and 375 seeds $\mathrm{m}^{-2}$.

$\mathrm{m}^{-2}$ for large grain varieties in shance (ITCF, 1978) is a population of 500-550 ears varieties in very fertile soils the objective is $600-700$ reserves; for smaller grain populations vary between 200 objective is $600-700$ ears $\mathrm{m}^{-2}$. End of winter seeds $\mathrm{m}^{-2}$. 
In the Schleswig-Holstein system very high ear numbers (at least 500 and, if possible, over 600 ears $^{-2}$ ) are desirable. The proponents of this system believe that high ear numbers can only be attained by high seed rates (about 400 grains $\mathrm{m}^{-2}$ ) so that the crop is formed by a large proportion of ears belonging to main stems and first-order tillers. Effland (1981) believes that ear density is the yield component playing the predominant role determining yield. It seems that, when the yield potential is very high (above $9 \mathrm{tha}^{-1}$ ), relatively high sowing rates are effective, especially when drilling small-grain varieties or varieties with low tillering capacity.

\section{Method of sowing (row spacing)}

Narrow row spacings are a popular subject for study. Within reasonable limits it is possible to examine the effect of a narrow row width, e.g. $8-10 \mathrm{~cm}$ compared with $16-20 \mathrm{~cm}$. The results are not unanimous. In trials carried out in Germany, an increase in yield of around $60 \mathrm{~kg} \mathrm{ha}^{-1} \mathrm{~cm}^{-1}$ of reduction in row spacing was observed (variation of row spacing between 20 and $10 \mathrm{~cm}$ ) (Heyland, 1981). In Belgian trials, Bodson et al. (1982) had no evidence to indicate that a yield difference is attributal to a reduction in row spacing.

\section{Nitrogen dressing}

The subject of nitrogen fertilization is one of the most widely studied in Europe, as it is in other countries. In the intensive production systems not only is there an increase in the total quantity of nitrogen used, but also in the number of applications required. Situations where a single application would be sufficient are rare; all the systems recommend at least two applications (system of balances, ITCF, France) and four, and even up to six, applications are sometimes used (Schleswig-Holstein).

There are two main methods of determining nitrogen dressings, whether or not they belong to a completely integrated system of cereal production. One technique is based on soil analysis results, carried out on a field-to-field basis, generally at the end of winter or beginning of spring. One such method is that referred to as the 'N-min method' developed by Wehrmann and coworkers (Scharpf and Wehrmann, 1975; Wehrmann et al., 1979) for the Hanover region and used also in other regions (e.g. Netherlands, Belgium) by other soil analysis laboratories. Other systems are based on 'keys of determination' which have the capacity to define, split-by-split, the dressing for each field as a function of factors characteristic of the fields being considered. These are the systems of Laloux, ITCF (system of balances), and of Schleswig-Holstein.

To determine nitrogen dressings the Laloux method takes into consideration the following factors:

(a) The soil richness in humus, or more precisely, an estimation of the nitrogen fertility of soils;

(b) The previous crop, its nature, its restitutions of fresh organic matter and its eventual residues of non-utilized nitrogen fertilizer; and

(c) The climate, essentially the climatic elements which concern mineralization and leaching during the course of the autumn/winter period. 
For the past few years the determination of nitrogen fertilizer doses has been supported by analytical results of mineral nitrogen profiles in the soil, for several 'specific' situations.

For the $I T C F$ system of balances successive splits, two or three in number, are determined in the following manner:

(a) For the first split at the end of winter the quantity of nitrogen to be applied is a function of the population and the stage of development of the crop, according to pre-determined dates, varying from 15 January (south-west zone) to 10 March (northern zone); the quantities will be from $90 \mathrm{~kg} \mathrm{Nha}^{-1}$ (wheat at three-leaf stage, low population less than 180 plants m${ }^{-2}$ ) to $30 \mathrm{~kg} \mathrm{~N} \mathrm{ha}^{-1}$ (wheat at three tillers plus stage, more than 300 plants $\mathrm{m}^{-2}$ ).

(b) The second split, at stem extension, is determined by the difference between the total quantity of nitrogen fertilizers, less the first split; if the result is greater than $120 \mathrm{~kg}$ nitrogen an application of a maximum of $80 \mathrm{~kg}$ nitrogen is recommended at the indicated growth stage and the remaining $40 \mathrm{~kg}$ nitrogen (or more) will be applied later, towards the flag leaf stage.

The total nitrogen quantity is determined by a balance in which the conditions of application are well defined and whose suitability has been established for northern and north-eastern regions of France. The elements of these balances are given in
Table 32.7.

TABLE 32.7. Elements to take into account for calculating the total quantity of nitrogen fertilizer according to the system of balances, ITCF, France

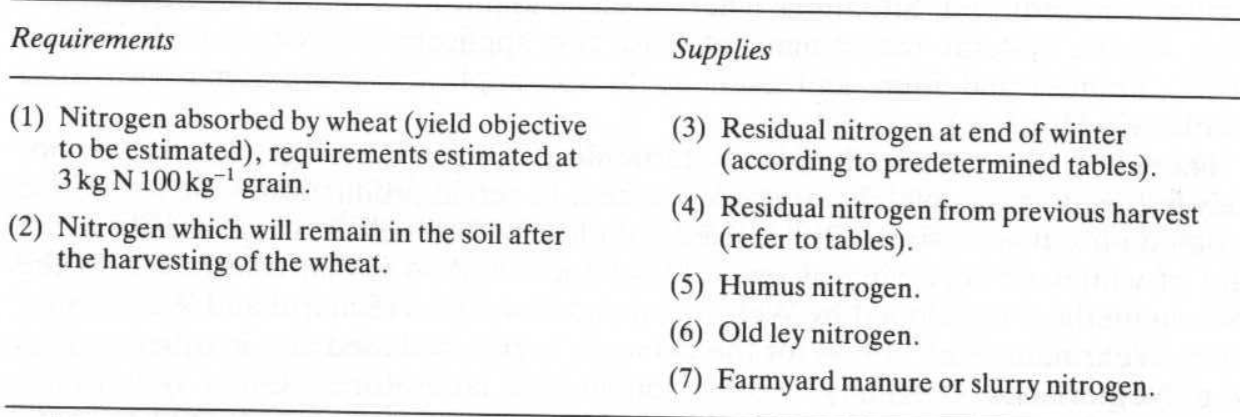

$(1)+(2)=$ total requirements; $(3)+(4)+(5)+(6)+(7)=$ supplies

Requirements less supplies $=$ Total quantity of nitrogen fertilizer

In the Schleswig-Holstein system nitrogen fertilization is aimed at supporting the very high ear populations. This means that there must be a constant supply of nitrogen available to the plants and this, in turn determines (a) the high level of nitrogen fertilization used, and (b) the division of this nitrogen fertilizer supply into a relatively large number of doses.

A further step in the area of nitrogen dressing would be the prediction, by model, of soil nitrogen behaviour, allowing a more accurate determination of fertilizer applications and lead to a more complete utilization of nitrogen by the plant. 


\section{Summary}

Since 1960 a number of cereal production systems have been developed in western Europe. Laloux (1967) was amongst the first to propose a complete system which was considered at that time as being intensive. Since then, new 'high-input' systems have been proposed, most notably that system originating in the region of Schleswig-Holstein.

This chapter gives a brief description of the 'Laloux' and 'Schleswig-Holstein' systems and also comparative results from 'low-input', 'moderate' and 'high-input' systems. From these comparisons it seems that the more intensive systems always permit a higher yield to be attained but are not always the more profitable.

Several aspects of intensification are also described, in particular those factors concerning drilling and the determination of nitrogen dressing for which actual research results and trends are given.

As a conclusion, it seems that profitable, intensive cereal growing can only be obtained by constant adaptation of 'systems' to environmental conditions, technical progress and economic climate.

\section{Acknowledgements}

The authors graciously acknowledge the assistance of their colleagues in the Dept. of Crop Husbandry, in particular J. Poelaert, J. Dohet and P. Nyst for their help in the preparation of this article. They are very grateful also to D. Duffy for the translation and other relevant remarks.

\section{References}

Ambolet, B. and maumene, J. (1981). Le blé dans le Nord-Bassin Parisien. Trois niveaux d'intensification comparés. Perspect. agric., 53, 14-21

BODSON, B., LALOUX, R., RIXHON, L. and POELAERT, J. (1982). Essais d'intensification de la culture des céréales. In Fumure et Protection Phytosanitaire des Céréales, pp. 1-8. Gembloux

COIC Y (1960). Les bases physiologiques de la nutrition et de la fertilisation rationnelle du blé Progressive Wheat Production, pp. 95-122. Genève, Centre d'Etude de l'Azote

Prost. agric., 45, 14-23

EAIVRE-DUPAIGRE, R. (1981). Systèmes de production et choix de stratégie dans l'exploitation agricole. Perspect. agric., 45, 112-114

HEYLAND, K. W. (1981). Versuchsgut Dikopshof. 262 pp.

HUGHES, R. (1981). Stratégie de la production du blé au Royaume-Uni. Perspect. agric., 45, 24-27

ITCF (1978). La fertilisation azotée du blé. $30 \mathrm{pp}$ 
LALOUX, R. (1967). Propos sur la fumure azotée du froment d'hiver. Faculté des Sciences Agronomiques, Gembloux, Belgium

LALOUX, R., POELAERT, J. and FALISSE, A. (1975). Fumure azotée des céréales. Revue agric., 5, 1173-1202 LAlouX, R., FAlisse, A. and poelaert, J. (1980). Nutrition and fertilization of wheat. In Wheat, pp. 19-24. Basle, Documenta Ciba-Geigy

LAlOUX, R., RIXHON, L., CROHAIN, A., BOdSON, B., POElaERT, J., DOHET, J., NYST, P. and COUVREUR, L. (1982). Essais d'intensification de la culture des céréales. Fumure et Protection photosanitaire des Céréales. Faculté des Sciences Agronomiques, Gembloux, Belgium

PELlOT, Ph. (1981). Systèmes de culture du blé dans le Nord de la France. Perspect. agric., 45, $102-106$ SCHARPF, H. C. and WEHRMANN, J. (1975). Die Bedeutung des Mineralstikstoff-vorrates des Bodens zu Vegetationsbeginn für die Bemessung der N-Düngung zu Winterweizen. Landw. Forsch. Sonderh., 32, $100-114$

WEHRMANN, J., WOllRinG, J., SCHARPF, H. C., MOLITOR, H. D. and BÖHMER, M. (1979). Praktische Erfahrungen und neue Ergebnisse mit der N min-methode. Dt. Landwirt. Geselsch. Mitt., 2, 67-69 